\title{
Co-evolution of vacancies and solute clusters during artificial ageing of Al-Mg-Si alloys
}

\author{
Mazen Madanat $\odot,{ }^{1}$ Meng Liu $\odot,{ }^{1,2, *}$ Xingpu Zhang $\odot,{ }^{1}$ Qianning Guo $\odot,{ }^{1}$ Jakub Č́žžek $\odot,{ }^{3}$ and John Banhart $\odot{ }^{1,2}$ \\ ${ }^{1}$ Technische Universität Berlin, Hardenbergstraße 36, D-10623 Berlin, Germany \\ ${ }^{2}$ Helmholtz Zentrum Berlin, Hahn-Meitner-Platz 1, D-14109 Berlin, Germany \\ ${ }^{3}$ Charles University, V Holešovičkách 2, 18000 Praha 8, Czech Republic
}

(Received 17 January 2020; accepted 15 May 2020; published 26 June 2020)

\begin{abstract}
Al-Mg-Si alloys with total solute contents ranging from 0.8 to $1.4 \mathrm{wt} \%$ were solutionized, quenched, and then artificially aged (AA) at $180^{\circ} \mathrm{C}$, after which positron annihilation lifetime spectroscopy was applied to obtain information about precipitation and vacancy evolution during the preceding ageing step. Hardness and electrical resistivity measurements were carried out to complement these measurements. AA was carried out in four different heating media, which allowed for varying the average heating rate from 2.4 to $170 \mathrm{~K} \mathrm{~s}^{-1}$. The main result of the study is that there is a competition between vacancy losses and precipitation. Any precipitation taking place during quenching or during heating to the AA temperature helps to prevent vacancies from going to sinks and allows them to assist in solute clustering. Higher solute content, slower heating to $180^{\circ} \mathrm{C}$, and natural preageing before AA were found to have a comparable effect.
\end{abstract}

DOI: 10.1103/PhysRevMaterials.4.063608

\section{INTRODUCTION}

The technologically important $6 X X X$ series of agehardenable alloys is based on the ternary system Al-MgSi. After solutionizing and quenching, artificial ageing (AA) at typically $180^{\circ} \mathrm{C}$ leads to the formation of a series of metastable precipitates that increase strength. $6 X X X$ alloys are well investigated and the precipitation sequence largely known. However, understanding multistage heat treatments or subtle influences of alloy composition is still difficult [1]. Even the simplest case-direct AA after quenching-bears some unknown problems. The earliest precipitates, also called "atom clusters", are assumed to have the fcc structure of the host metal and to transform later to monoclinic GuinierPreston (GP) zones and $\beta$ " precipitates [2-4], but how this happens and how precipitates grow is not known with certainty [5,6]. Moreover, the role of vacancies in the early stage of AA is not clear. After solutionizing and quenching, the high site fraction of vacancies formed at the solutionizing temperature is partially preserved as nonequilibrium excess vacancies. Unlike during natural ageing (NA), which is driven by excess vacancies for a long time ( $\sim$ weeks), during AA excess vacancies anneal out much faster and the vacancy site fraction approaches the equilibrium value at the AA temperature, but how fast this happens is not known because vacancy loss is influenced by both vacancy sinks such as dislocation

\footnotetext{
*Present address: Chinalco Materials Application Research Institute Co., Ltd., Beijing, China; Corresponding author: liumeng@ cmari.com

Published by the American Physical Society under the terms of the Creative Commons Attribution 4.0 International license. Further distribution of this work must maintain attribution to the author(s) and the published article's title, journal citation, and DOI.
}

jogs and grain boundaries [7] and by growing clusters. Solute supersaturation is also a crucial factor since it provides the driving force for precipitation. How it varies during AA is not exactly known.

We intend to contribute to the understanding of the role of vacancies, solute atoms, and solute clusters especially in the early stages of AA. We study very short AA treatments down to $0.3 \mathrm{~s}$ and also vary the heating rate from "room temperature" to $180^{\circ} \mathrm{C}$ - the usual AA temperature for which a lot of data are available - aiming at understanding how the kinetics of vacancy losses and cluster formation are linked to each other. The main tool employed is positron annihilation lifetime spectroscopy. This method is sensitive to both vacancies and atom clusters/precipitates and has been applied previously to explain the NA behavior in identical or similar alloys [8-10]. The high sensitivity to vacancies is actually unique and even small changes in vacancy fraction can be detected [11]. Clusters can also be detected by atom probe tomography but as the present study involves very early stages of clustering any quantitative analysis is very challenging or even not possible [12]. X-ray small-angle scattering would fail due to insufficient elemental contrast between $\mathrm{Al}, \mathrm{Mg}$, and Si [13]. Only electrical resistivity measurement could provide evidence on changes of both vacancies and clusters, which is why it is applied to provide some complementary data [14].

We study pure ternary model alloys to keep out possible effects of both common solute atoms such as $\mathrm{Cu}$ that might influence precipitation and intermetallic-forming elements such as $\mathrm{Fe}$ and $\mathrm{Mn}$ that might lower the Si content. Most investigations are carried out on a lean alloy containing $\sim 0.4 \mathrm{wt} \%$ of both $\mathrm{Mg}$ and $\mathrm{Si}$, which is similar to the industrial alloy 6060 , and an alloy higher in solute containing $\sim 0.6 \mathrm{wt} \%$ $\mathrm{Mg}$ and $\sim 0.8 \mathrm{wt} \% \mathrm{Si}$, which is similar to the industrial alloy 6005 (all in wt \%). One objective is to address the pronounced differences in ageing behavior between lean Al-Mg-Si alloys $(\mathrm{Mg}+\mathrm{Si} \leqslant \sim 1 \%)$ and more concentrated ones. 
TABLE I. Compositions of alloys as determined by optical emission spectroscopy and given in wt \% (at \%). The purities of the base elements were $\mathrm{Al} 5 \mathrm{~N}, \mathrm{Mg} 4 \mathrm{~N}, \mathrm{Si}$ N . An analysis of alloy 6-8 showed the following impurities (by mass): $\mathrm{Bi}, \mathrm{Sn}:<10 \mathrm{ppm}$; Ga, Fe, Zn: $<5$ ppm; In, P: < 4 ppm; Co, Cr, Cu, Mn, Pb, Sb, Sr, Ti: < 2 ppm; $\mathrm{B}, \mathrm{Be}, \mathrm{Ca}, \mathrm{Cd}, \mathrm{Li}, \mathrm{Na}, \mathrm{V}, \mathrm{Zr}:<1 \mathrm{ppm}$.

\begin{tabular}{lcc}
\hline \hline Alloy designation & $\mathrm{Mg}$ & $\mathrm{Si}$ \\
\hline $4-4$ & $0.39(0.43)$ & $0.40(0.38)$ \\
$5-5$ & $0.46(0.51)$ & $0.54(0.52)$ \\
$4-10$ & $0.40(0.44)$ & $1.01(0.97)$ \\
$6-8$ & $0.59(0.66)$ & $0.79(0.76)$ \\
$8-6$ & $0.80(0.89)$ & $0.61(0.59)$ \\
$10-4$ & $1.02(1.13)$ & $0.41(0.39)$ \\
\hline \hline
\end{tabular}

\section{EXPERIMENT}

\section{A. Samples and heat treatment}

Pure ternary aluminium alloys were provided by Hydro Aluminium, Bonn, as described elsewhere [8,13]. Compositions are specified in the format " $n-m$," where $n$ stands for the $\mathrm{Mg}$ and $m$ for the Si content in 1/10 wt \% throughout this paper; see Table I.

Samples of $10 \times 10 \times 1 \mathrm{~mm}^{3}$ size were prepared for both positron lifetime and hardness measurements. Samples were ground and ultrasonically cleaned with alcohol for clean surfaces. Solution heat treatment (SHT) was performed at $540^{\circ} \mathrm{C}$ for $1 \mathrm{~h}$ in an argon atmosphere followed by ice water quenching. After quenching, one of the following heat treatments was carried out: (i) natural ageing (NA) at "room temperature" (i.e., $20 \pm 2{ }^{\circ} \mathrm{C}$ ); (ii) artificial ageing (AA) in one of four different media (see below) followed by measurement at $\sim 20^{\circ} \mathrm{C}$; (iii) natural preageing (NPA) at room temperature for 5,30 , or 80 min followed by AA, after which positron lifetime measurements were conducted at $\sim 20^{\circ} \mathrm{C}$ again.

Four different AA media held at $180{ }^{\circ} \mathrm{C}$ were used to study the influence of the heating rate to $180{ }^{\circ} \mathrm{C}$ : (i) Highly thermally conductive and low-melting liquid metal ("LM") Bi57Sn43. The Al-Mg-Si samples were kept in motion to ensure faster heating to $180{ }^{\circ} \mathrm{C}$. After immersion into the metal the sample surfaces were checked for possible Bi-Sn residues but were found not to be wetted by the Bi-Sn alloy. The positron lifetime in Bi57Sn43 was measured to be $\sim 240$ ps. No such lifetime contribution was found in any spectrum. (ii) Silicon oil ("oil") as widely used as AA medium. Samples were also kept in motion during AA. (iii) A molten salt ("MS") mixture of $53 \% \mathrm{KNO}_{3}+40 \% \mathrm{NaNO}_{2}+7 \% \mathrm{NaNO}_{3}$ with a low melting point of $142{ }^{\circ} \mathrm{C}$ [17]. During AA, the samples were kept in a resting position to obtain a slower heating rate. (iv) Controlled heating plates ("HP") that heat linearly at slower rates. Samples were sandwiched between two aluminium buffer plates to damp temperature oscillations caused by the temperature controller.

For all heating modes, a 0.5 -mm-thick thermocouple was inserted into holes drilled into an edge of test specimens to measure the temperature courses given in Fig. 1. The time to reach $170^{\circ} \mathrm{C}$ is $0.9 \mathrm{~s}$ for LM, which we call "fast heating," $6 \mathrm{~s}$ for oil and $10 \mathrm{~s}$ for MS, which we call "moderate heating," and $63 \mathrm{~s}$ for the heating plate, "slow heating." The corresponding

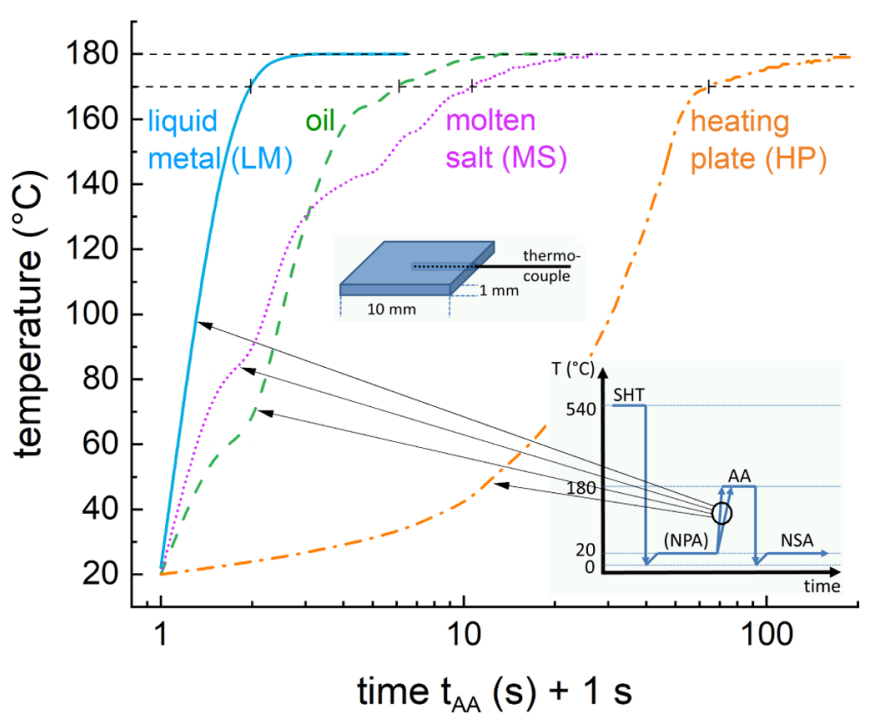

FIG. 1. Heating profiles applying four different media for AA at $180^{\circ} \mathrm{C}$. The starting time is arbitrarily set to $1 \mathrm{~s}$ to be able to use a logarithmic time scale. The linear heating ramp of the heating plate appears as an exponential on this scale. The heating curve in molten salt shows some kinks as upon immersion of a cold sample some salt first solidifies and then melts after a short time. In oil, a deviation of slope is observed around $70^{\circ} \mathrm{C}$ for an unknown reason. The short vertical dashes mark the times needed to reach $170^{\circ} \mathrm{C}$, from which we calculate an average heating rate (the time to reach $180^{\circ} \mathrm{C}$ is not well defined due to the near-asymptotic approach of the target temperature). Insets: setup of temperature measurement and general heating program of experiments.

average heating rates up to $170{ }^{\circ} \mathrm{C}$ are $170,25.5,15.3$, and $2.4 \mathrm{~K} \mathrm{~s}^{-1}$, respectively.

\section{B. Positron lifetime measurements}

Most positron lifetime measurements were carried out at the laboratory in Berlin ("B"). Two identical samples were assembled to a sandwich with the positron source in between and an aluminium foil wrapped around it. This was done either after quenching from SHT or after AA and required about 2 min during which the sample remained at $\sim 20^{\circ} \mathrm{C}$. We refer to the Supplemental Material [18], Sec. S1, for measurement details. Positron annihilation spectra were then measured continuously at $\sim 20^{\circ} \mathrm{C}$. Either a one-component lifetime $\tau_{1 C}$ was obtained, or decompositions into two components labelled by numbers $\tau_{i}$ in the order of increasing lifetime and the corresponding intensities $I_{i}$. As it has been found that the higher lifetime component contains two components [9] we will adopt the notation $\tau_{1}$ and $\tau_{2+3}$ for the two components even if they cannot be resolved in a specific case. The quantities $I_{i}$ are fitting parameters that have to be converted to physical properties using a model such as the trapping model. Spectra were also measured at Charles University in Prague ("P") at $-40{ }^{\circ} \mathrm{C}$ using a spectrometer with a higher time resolution [19] in order to slow down ageing kinetics and to be able to collect $>5 \times 10^{6}$ annihilation events in positron spectra for a reliable two-component analysis. 


\section{Hardness and electrical resistivity measurement}

Hardness tests were carried out after a given AA time using a Vickers microhardness tester MHT-10. The load force was $1 \mathrm{~N}$ and the dwell time $10 \mathrm{~s}$. Ten indentations were averaged for each sample. Electrical resistivity was measured on $\sim 400$ $\mathrm{mm}$-long and 0.82-mm-thick coiled wires using a four-point setup as described earlier [16]. After solutionizing, quenching, and brief drying the coil was immersed into liquid nitrogen and the resistivity measured there. Then the coil was dipped into either $\mathrm{LM}$ or oil at $180^{\circ} \mathrm{C}$ for $10 \mathrm{~s}$, then quenched in water, after which resistivity was measured in liquid nitrogen again.

\section{RESULTS}

\section{A. Positron lifetime}

\section{Artificial ageing of lean alloy 4-4}

One-component positron lifetime. The evolution of $\tau_{1 C}$ versus AA time after heating in different media is shown in Fig. 2(a). The symbol labelled "AQ" corresponds to the as-quenched state captured $\sim 2$ min after quenching. Measurements after AA were carried out at $\sim 20^{\circ} \mathrm{C}$, during which $\tau_{1 C}$ evolved due to natural secondary ageing (NSA). See the Supplemental Material [18], Sec. S1, for how values corresponding to zero NSA are determined.

The course of $\tau_{1 C}$ depends on the medium used for AA. Fast heating in LM causes $\tau_{1 C}$ values as low as $\sim 163 \mathrm{ps}$. This is a reduction by $80 \mathrm{ps}$ with respect to the value measured directly after quenching (AQ). For $1 \mathrm{~s}$ of AA, the values vary in the 11 experiments carried out by manually dipping a sample into the metal. $\tau_{1 C}$ does not change much up to $5 \mathrm{~min}$ of AA, with possibly a slight minimum for $\sim 3 \mathrm{~s} \mathrm{AA}$ in LM. Higher $\tau_{1 C}$ values were measured after moderate-rate heating in oil, namely 218 and 197 ps after 2 and 10 s, respectively, with an ensuing decrease to $185 \mathrm{ps}$ for $1 \mathrm{~min}$ of AA. The maximum $\tau_{1 C}$ decrease caused by AA in oil is therefore much lower than for fast heating. AA in MS or on the heating plate for up to a few minutes yields a similar course but even slightly higher minimum values. In all heating media, $\tau_{1 C}$ starts to increase for longer AA and $\tau_{1 C} \sim 235 \mathrm{ps}$ is found after long AA in oil.

Two-component positron lifetimes. In some cases it was possible to decompose spectra into two contributions $\left(\tau_{1}, \tau_{2+3}\right)$ and the corresponding intensities $\left(I_{1}, I_{2+3}\right)$; see Figs. 2(b) and 2(c). Each value represents a state after AA and is based on data accumulated during NSA for 15-30 min, during which $\tau_{1 C}$ remains constant or is only slowly changing. The highest heating rate in LM leads to a different course than moderate and slower heating in oil, molten salt, or on the heating plate. $1 \mathrm{~s}$ in LM produces $\tau_{2+3} \sim 213 \mathrm{ps}$ and an intensity $I_{2+3}$ of $54 \%$. The high-precision measurement after $5 \mathrm{~s} \mathrm{AA}$ in LM yields $\tau_{2+3}=215 \pm 1 \mathrm{ps}, I_{2+3}=50 \pm 1 \%$ at $-40^{\circ} \mathrm{C}$; see crossed squares. After up to $5 \mathrm{~min}$ of AA in LM, these values do not change notably, but after $30 \mathrm{~min}$ of AA $I_{2+3}$ increases to $68 \%$. Even longer AA lets $\tau_{2+3}$ further increase and reach $235 \mathrm{ps}$, while $I_{2+3}$ goes up to $75 \%$. Slower heating either in oil, MS, or on the heating plate yields $I_{2+3} \sim$ $80 \%$ all through AA, Fig. $2(\mathrm{c})$, while the measured $\tau_{2+3}$ values are about the same as for AA in LM. The longest AA times
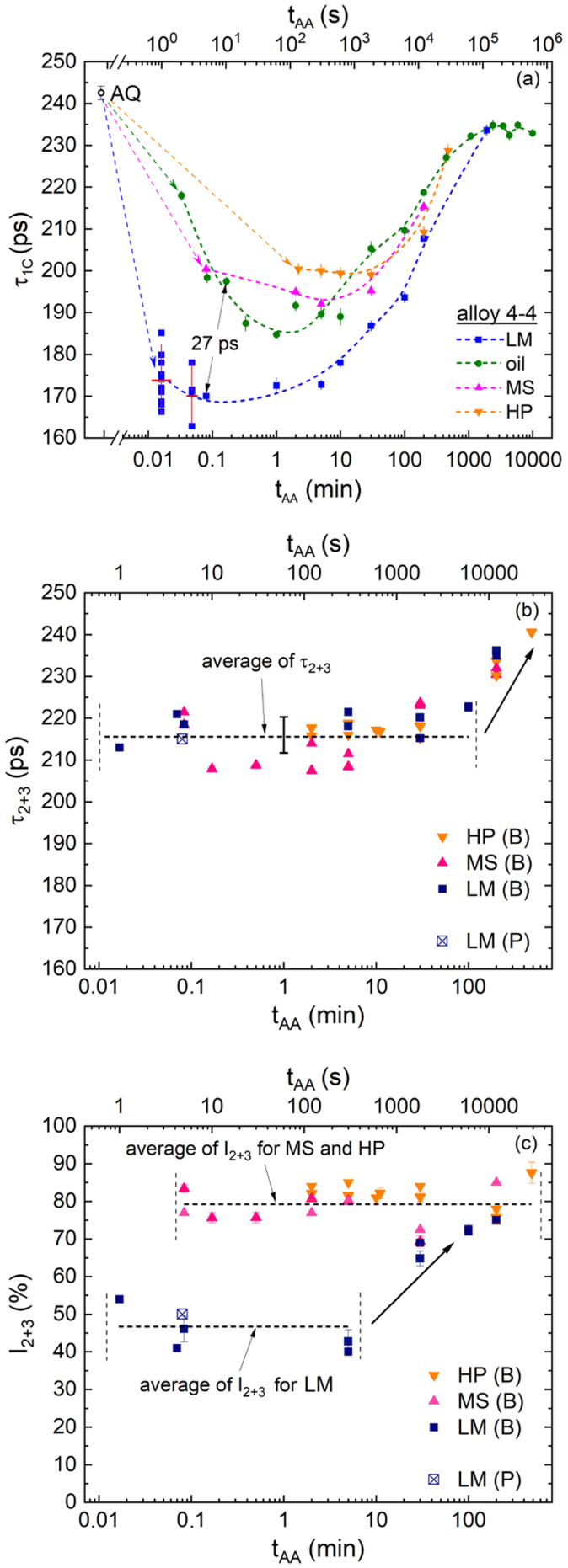

FIG. 2. Evolution of positron lifetime $\tau_{1 C}$ in alloy 4-4. (a) $\tau_{1 C}$ as a function of AA time (at $180^{\circ} \mathrm{C}$ ) in different heating media. Error bars refer to individual fitting uncertainty except for the red bars, where standard deviation of averages of different measurements and uncertainty in AA time are expressed. Double sided arrow corresponds to the one in Fig. 9. (b),(c) Trap lifetimes $\tau_{2+3}$ and intensities $I_{2+3}$ as derived from positron lifetime decompositions for alloy 4-4. Different symbols specify the AA medium used. All positron lifetime measurements were carried out at $\sim 20^{\circ} \mathrm{C}$ (spectrometer "B") except for the one represented by crossed squares that was measured in high resolution at $-40^{\circ} \mathrm{C}$ ("P"). The broken lines indicate averages of regimes considered approximately constant. Arrows mark the trends discussed in the text. 


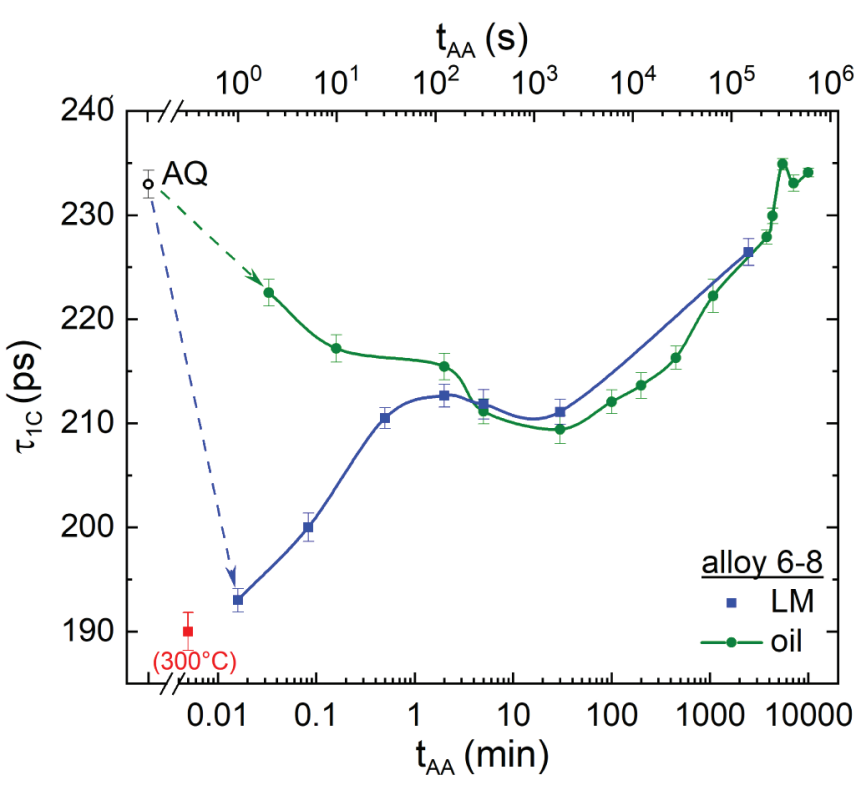

FIG. 3. Evolution of the one-component positron lifetime $\tau_{1 C}$ in alloy 6-8 as a function of AA time (at $180^{\circ} \mathrm{C}$ ) in different heating media. Only the red symbol corresponds to $0.3 \mathrm{~s}$ annealing at $300^{\circ} \mathrm{C}$.

( $\geqslant 200 \mathrm{~min}$ ) let $\tau_{2+3}$ increase to $235 \mathrm{ps}$. Lines and arrows in Figs. 2(b) and 2(c) underline this description.

\section{Artificial ageing of more concentrated alloy 6-8}

One-component positron lifetime. Figure 3 shows $\tau_{1 C}$ of alloy 6-8 measured after AA in LM and oil. $1 \mathrm{~s}$ of AA in LM decreases $\tau_{1 C}$ by $\sim 40 \mathrm{ps}$ compared to the as-quenched state, while for $2 \mathrm{~s} \mathrm{AA}$ in oil, $\tau_{1 C}$ is reduced only by $\sim 10 \mathrm{ps}$. Increasing the AA time leads to a continuous increase to 213 ps after 2 min AA in LM followed by a slight dip down to 211 ps after 30 min AA, while a continuous decrease to a minimum of 209 ps after 30 min AA in oil is observed. Even longer AA times cause an increase of $\tau_{1 C}$ up to $\sim 235 \mathrm{ps}$ as in alloy 4-4.

An extra experiment was carried out by dipping a sample into $\mathrm{LM}$ held at $300^{\circ} \mathrm{C}$ for $\sim 0.3 \mathrm{~s}$ in order to achieve an even higher heating rate than in $\mathrm{LM}$ at $180^{\circ} \mathrm{C}$. The end temperature in this experiment was estimated $200-230^{\circ} \mathrm{C}$. $\tau_{1 C}$ after this treatment is even lower than after AA for $1 \mathrm{~s}$ at $180^{\circ} \mathrm{C}$ in $\mathrm{LM}$ (red point in Fig. 3).

Two-component positron lifetimes. Reliable lifetime decompositions in alloy 6-8 are more difficult than in alloy 4-4 and only after AA for $0.3 \mathrm{~s}$ in $\mathrm{LM}$ at $300^{\circ} \mathrm{C}$ was a clear indication for two-component behavior found with a trap contribution $I_{2+3}=84 \%$.

\section{Further experiments}

Figure 4 displays $\tau_{1 C}$ after short AA for $1 \mathrm{~s}$ in LM for four more alloys, namely 5-5, 4-10, 8-6, and 10-4; see Table I. The value obtained for alloy 5-5 lies slightly above that for alloy 4-4, while the values for the alloys with a combined $\mathrm{Mg}$ and $\mathrm{Si}$ content of $\sim 1.4 \mathrm{wt} \%$ are much higher and lie close together. Figure 4 also presents $\tau_{1 C}$ in alloy 4-4 after a combination of a NPA step of either 5, 30, or $80 \mathrm{~min}$, see upper axis, and short

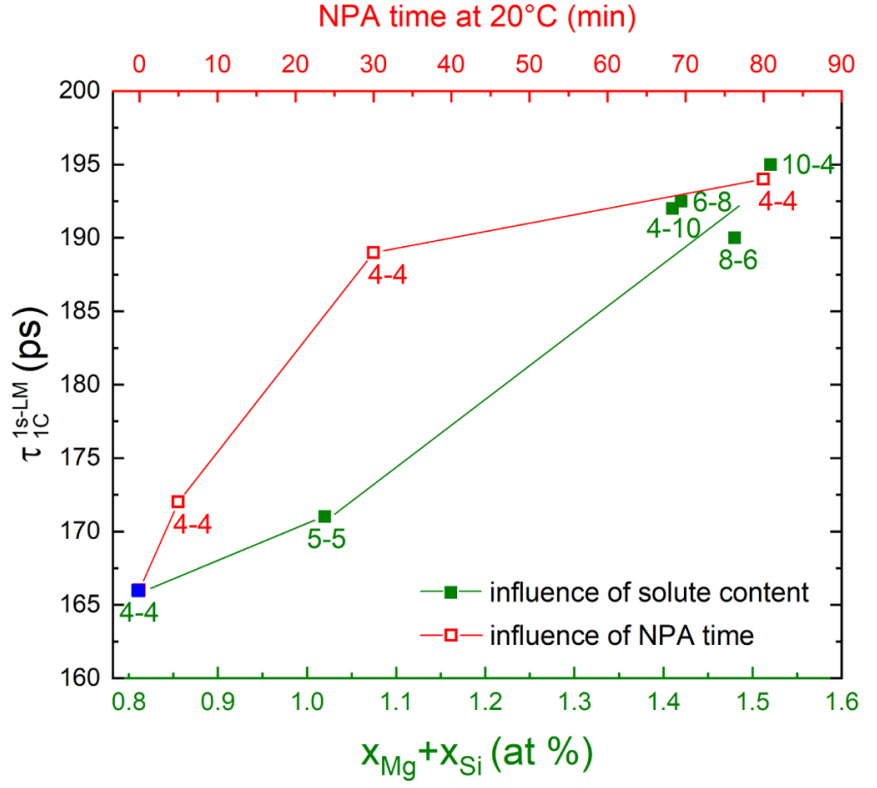

FIG. 4. $\tau_{1 C}$ after $1 \mathrm{~s}$ of AA in LM for various alloys with different $\mathrm{Mg}$ and $\mathrm{Si}$ contents (full symbols). Data for alloys 4-4 and 6-8 are the same as in Fig. 2(a) (lowest value chosen) and Fig. 3. For alloy 4-4, an additional NPA step $(5,30$, or $80 \mathrm{~min})$ has been included before AA (open symbols).

AA for $1 \mathrm{~s}$ in LM. NPA does have a strong effect on $\tau_{1 C}$ after $\mathrm{AA}$ as it increases it by up to $25 \mathrm{ps}$.

\section{B. Hardness}

\section{Artificial ageing of lean alloy 4-4}

Figure 5 shows the evolution of hardness in alloy 4-4 during $\mathrm{AA}$ in oil and compares it to $\tau_{1 C}$. A negligible initial

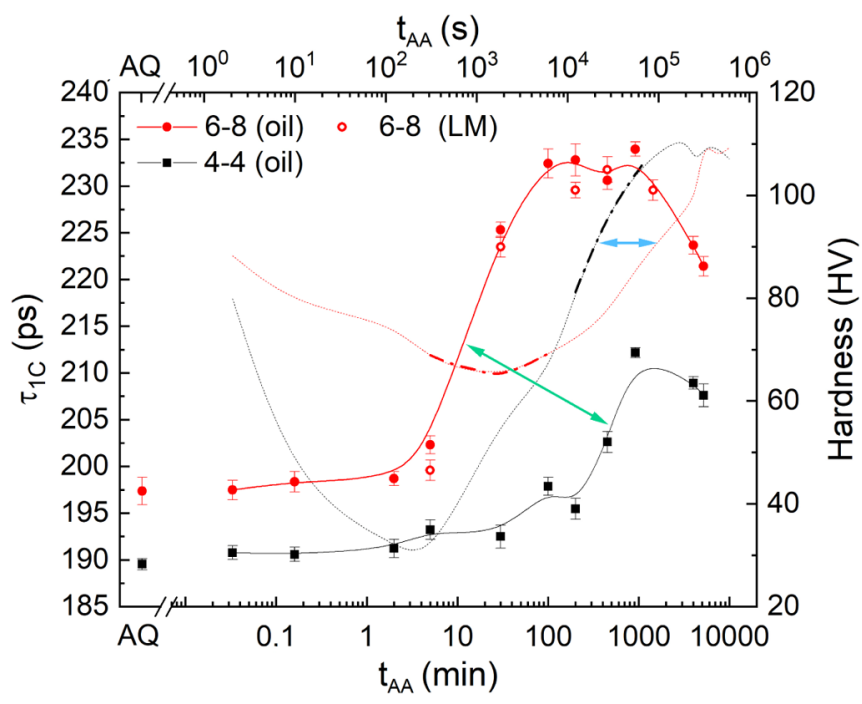

FIG. 5. Hardening of alloy 4-4 and 6-8 at $180^{\circ} \mathrm{C}$ in oil (and in LM for some cases). The thin broken lines represent the positron lifetimes $\tau_{1 C}$ taken from Figs. 2(a) and 3. On these lines, the dash-dotted sections emphasize the regions of main hardening. The double-sided arrows show how the two alloys differ in main hardening (green, 4-4 later increase) and final increase of $\tau_{1 C}$ (blue, 6-8 later). 


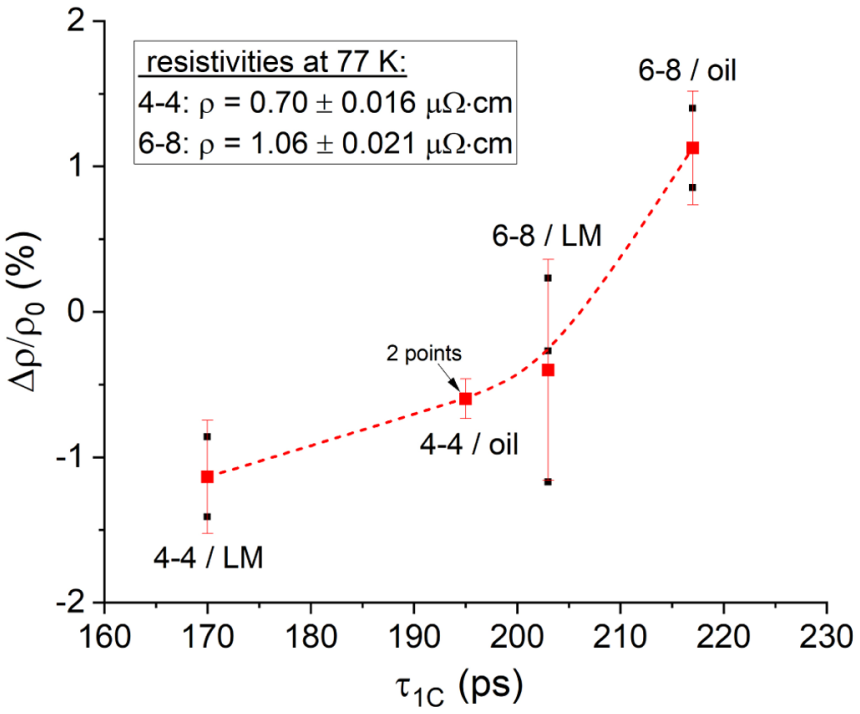

FIG. 6. Relative change of electrical resistivity during AA for $10 \mathrm{~s}$ measured for two alloys and two media (LM, oil). Black points are individual measurements, red points are averages. The data are related to positron lifetimes derived from Figs. 2(a) and 3.

change in hardness up to 2 min of AA is followed by an increase to a maximum of $70 \mathrm{HV}$ after $\sim 1000$ min of AA, after which overageing commences. The main increase in hardness takes place after $200 \mathrm{~min}$ of $\mathrm{AA}$, which is later than the increase of $\tau_{1 C}$ that sets in already after 5 min of AA. Overageing reduces hardness, but not $\tau_{1 C}$.

\section{Artificial ageing of concentrated alloy 6-8}

The hardening response of alloy 6-8 shows a negligible change during the first 2 min of AA in oil, followed by a slight increase up to $5 \mathrm{~min}$ of AA. The further increase of hardness to $93 \mathrm{HV}$ coincides with a shallow minimum of $\tau_{1 C}$ after $30 \mathrm{~min}$ of AA. A maximum of hardness was achieved after $100 \mathrm{~min}$ AA, followed by a plateau ranging between 100 and $110 \mathrm{HV}$ up to $\sim 15 \mathrm{~h}$ of AA. Hardness therefore peaks earlier than $\tau_{1 C}$, which takes $3.5 \mathrm{~d}$ to peak. Overageing for long AA times is pronounced. Figure 5 also shows some hardness values of samples AA in LM (open symbols), which point to a negligible influence of the AA medium.

\section{Electrical resistivity}

Electrical resistivity changes during $10 \mathrm{~s}$ of AA in LM and in oil are shown in Fig. 6 (as a function of $\tau_{1 C}$; see discussion in Sec. IV A 4). Such a short ageing time was chosen because the positron lifetimes in Figs. 2(a) and 3 show a large difference between quenching in LM and oil for short AA and a corresponding difference in electrical resistivity was hoped to be seen. The shortest AA times, e.g., $1 \mathrm{~s}$, were hard to realize due to the size and the handling requirements of the coils, which is why $10 \mathrm{~s}$ was chosen. Except for alloy 6-8 treated in oil, the electrical resistivity decreases during such short AA. The effects are small (ranging from $-1 \%$ to $+1 \%$ ) and there is some experimental scatter, probably caused by variations of the manually conducted experiments including transfer between various heat baths during which some uncontrolled temperature changes and some mechanical deformation of the coil cannot be excluded. There is a clear trend that fast heating in the lean alloy reduces resistivity, whereas slow heating in the concentrated one increases it.

\section{DISCUSSION}

Positron lifetime spectra in complex systems such as Al$\mathrm{Mg}-\mathrm{Si}$ alloys containing vacancies and different types of precipitates are rarely caused by annihilation in just one kind of trap. Instead, competitive annihilation in different ways is likely: (i) Annihilation in the free bulk without any trapping. If all positrons do this, their corresponding lifetime will be around 160 ps as we measured on well annealed $\mathrm{Al}$ and as it is reported in the literature [20,21]. If some positrons annihilate in traps, the lifetime of the untrapped positrons is reduced to $\tau_{1}<160 \mathrm{ps}$ (so-called "reduced bulk lifetime") [11]. (ii) Positron trapping and annihilation in monovacancies with a lifetime of 240-250 ps [20,21]. If a vacancy forms a complex with either a $\mathrm{Mg}$ or $\mathrm{Si}$ atom it has been estimated that the lifetime is modified only marginally (1-3 ps increase for $\mathrm{Mg}$, $1-2$ ps decrease for $\mathrm{Si}$ ) $[8,22,23]$. For the case that vacancies are surrounded by more $\mathrm{Mg}$ and $\mathrm{Si}$ atoms (vacancy-cluster complex), there are no reliable data for the corresponding lifetime. (iii) Vacancy-free clusters of $\mathrm{Mg}$ and $\mathrm{Si}$ atoms, with possibly some $\mathrm{Al}$ in between, can also trap positrons. Lifetimes of 200 ps [8], 214 ps [24], or 215 ps [9] have been used. Ordered coherent clusters (or "GP zones") and semicoherent $\beta$ " precipitates are expected to give rise to positron lifetimes slightly lower than the disordered clusters formed during NA, e.g., 208-210 ps [24]. As coherency between precipitates and the surrounding lattice decreases during prolonged ageing the associated positron lifetime increases. Values above $250 \mathrm{ps}$ have been suspected for late stages [25]. As the use of the terms "cluster", "GP zone", or "(early) precipitate" might create confusion we shall use the term "cluster" for any small initial aggregation of atoms in the following.

In this paper, we assume that positrons annihilate either in the bulk (untrapped, lifetime $\tau_{1} \leqslant 160 \mathrm{ps}$ ), in defects related

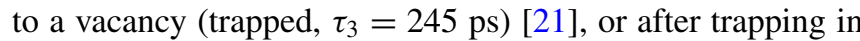
vacancy-free solute clusters or $\beta$ " precipitates where the lifetime $\tau_{2}$ initially ranges from typically 210 to $215 \mathrm{ps}$ [24] and eventually increases markedly once they have evolved into $\beta$, We neglect annihilation at grain boundaries and dislocations, and that clusters might have a range of different sizes and compositions (which in turn would lead to a range of positron lifetimes). We also neglect that the positron lifetime in vacancies is modified by the site occupation around them. Currently, there is no way to measure or calculate such lifetime distributions. In many cases, we measure a one-component positron lifetime $\tau_{1 C}$ only and have to deduce indirectly what might have changed its value during ageing. As positrons can annihilate in three different ways, changes of the average of the three partial lifetimes can be explained by an increase or decrease of one or more of the three contributions as outlined in Fig. 7.

The evolution of $\tau_{1 C}$ during NA has been studied previously [8-10] and is also given in the Supplemental Material 


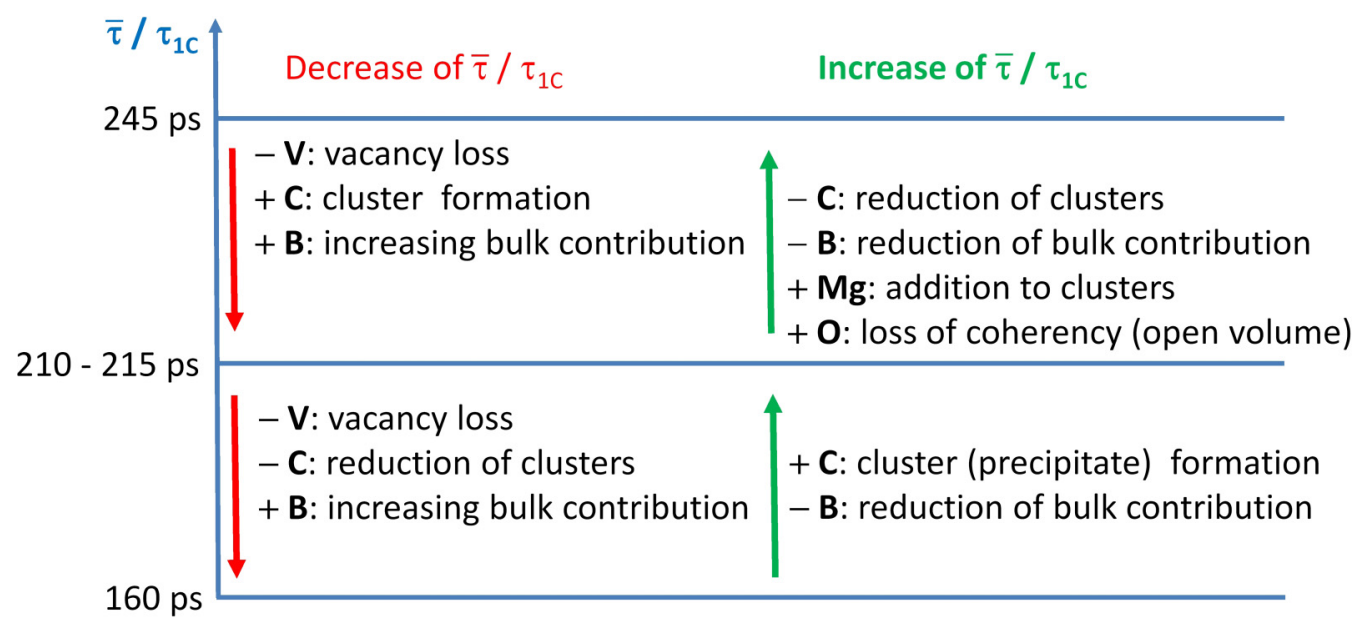

FIG. 7. Alternative mechanisms governing the change of the averaged $(\bar{\tau})$ or one-component positron lifetime $\left(\tau_{1 C}\right)$ during ageing. " + " and "-" denote an increase or decrease of a specific contribution. In this paper, vacancy (V) loss, clustering (C), loss of coherency (O), and the change of bulk annihilation (B) are discussed. Change of $\mathrm{Mg}$ content (Mg) governs natural ageing [8] and is not relevant here.

[18] (Fig. S1, full symbols). The first $\tau_{1 C}$ value measured after quenching is $243 \mathrm{ps}$ in alloy $4-4$ and $233 \mathrm{ps}$ in alloy 6-8. Previous work has shown that in alloy 4-4, at least $85 \%$ of the positrons annihilate in vacancy-related traps in this as-quenched state [9]. The initial value in alloy 6-8 is 10 ps lower in accordance with Ref. [8]. Possibly during quenching clustering sets in and the corresponding positron trapping component with a typical lifetime $\sim 215$ ps reduces $\tau_{1 C}$. The extent of such clustering is difficult to quantify since clustering and vacancy losses both lower the average positron lifetime. Temperature-dependent positron annihilation experiments have shown that clusters formed during initial NA are mostly shallow positron traps, i.e., notably trap only far below $20^{\circ} \mathrm{C}$, but grow to deep traps in the course of NA $[9,26]$. Therefore, the initial state after quenching contains quenched-in vacancies and some initial (shallow and deep trap) clusters and determines what happens during ensuing AA.

In all the alloys, even the shortest AA reduces $\tau_{1 C}$ markedly. According to Fig. 7, this indicates the loss of vacancies that are present in high numbers in the as-quenched state and possibly the formation of some clusters. For the shortest AA times, the initial values of $\tau_{1 C}$ vary a lot and range from 163 to $222 \mathrm{ps}$ depending on the alloy and heating conditions. $\tau_{1 C}$ reaches a minimum value in all but one case (alloy 6-8, LM), after which it increases again to a final value up to $235 \mathrm{ps}$. This increase is associated with the formation of positron traps in which positrons live longer; see Fig. 7.

As the effects governing early AA differ from those acting in intermediate or late AA stages, we shall group the following discussion according to ageing time and provide a theoretical background in the respective section where it is needed. We shall first discuss the measured data for "short AA" that leads from the high $\tau_{1 C}$ after quenching to a minimum value, then for "intermediate AA" that features a reincrease of $\tau_{1 C}$ to 210 $215 \mathrm{ps}$ and finally for "long AA" that is characterised by a very pronounced further increase of $\tau_{1 C}$. The main emphasis of this paper lies on short AA since this is the least explored regime and positrons are especially sensitive here.

\section{A. Short AA times}

\section{Interpretation of experiments}

The most pronounced decrease of $\tau_{1 C}$ is observed in alloy 4-4 dipped into LM for just $1-5 \mathrm{~s}$. Low values just slightly above the value for defect-free $\mathrm{Al}(160 \mathrm{ps})$ indicate that most vacancies have been eliminated and the number of clusters that might have formed is limited or they do not trap positrons at $20^{\circ} \mathrm{C}$. The positron lifetime spectrum exhibits two distinct components-Figs. 2(b) and 2(c) -with $I_{2+3} \sim$ $50 \%$. Technically, this means that roughly one-half of all positrons annihilate in the bulk because they do not encounter a vacancy or cluster on their diffusion paths through the alloy.

If all positron traps were vacancies, the two-state trapping model [11] could tell us the fraction of vacancies. Figure 8 (black dashed-dotted lines) shows that the lowest measured value for $\tau_{1 C} \approx \bar{\tau}$ of $163 \mathrm{ps}$ in Fig. 2(a) corresponds to a site fraction of vacancy-related defects of $x_{v}=5 \times 10^{-7}$ (solid triangle). This can be compared to the fraction directly after quenching, $x_{v}=7.5 \times 10^{-5}$ (open triangle), following from an average positron lifetime of 230 ps estimated for that case (see the Supplemental Material [18], Sec. S3, for more information).

Such values for $x_{v}$ can be compared to results obtained for $\mathrm{Al}-\mathrm{Cu}-\mathrm{Mg}$ alloys. Depending on the $\mathrm{Mg}$ content, $x_{v}$ after quenching ranges from $5 \times 10^{-6}$ to $4.5 \times 10^{-5}$, and $\mathrm{AA}$ for $60 \mathrm{~s}$ reduces these values by a factor of 12 to 3 , respectively ([27], Table I). This reduction is much less than in our alloy 4-4 (factor 150) but it has to be considered that AA was in oil there, the overall solute content was higher, and clustering kinetics should be different in this alloy system. However, the overall trend is similar.

As the scatter of individual two-component decompositions can be considerable we have averaged all the measurements up to 100 min of AA; see Fig. 2(b). Accordingly, $\tau_{2+3}$ is on average $216 \mathrm{ps}$ after short AA and not $245 \mathrm{ps}$ as the two-state trapping model suggests (red dash-dotted line in Fig. 8). This average agrees very well with a single value 


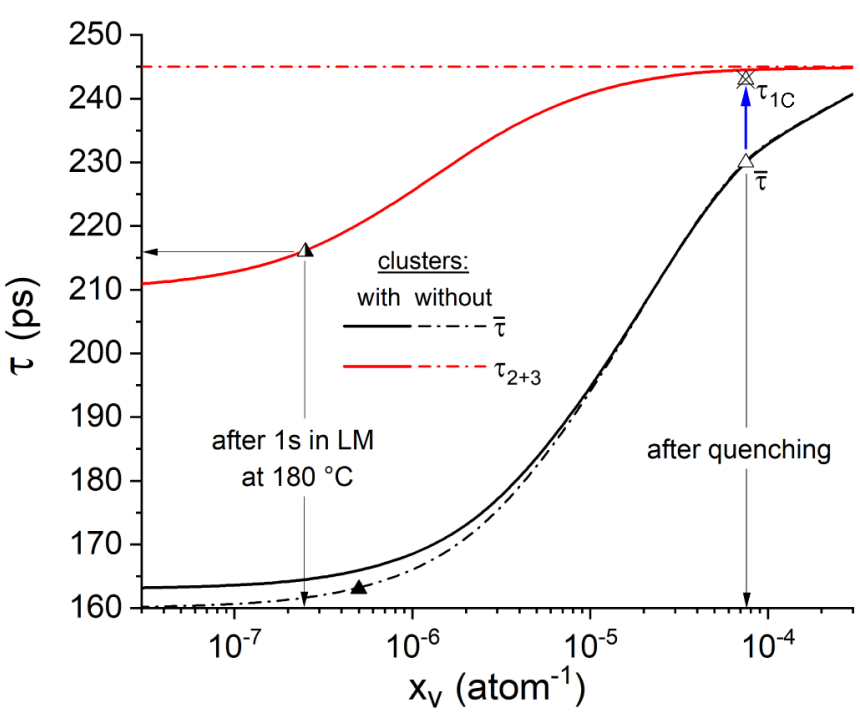

FIG. 8. Relationship between average $(\bar{\tau})$ or trap-related $\left(\tau_{2+3}\right)$ positron lifetimes and the site fraction of vacancies $x_{v}$ as calculated from the trapping models defined in Ref. [11] and using a bulk lifetime of $\tau_{b}=160 \mathrm{ps}$, an optional cluster contribution given by $\tau_{c}=210 \mathrm{ps}$ and a trapping rate $\kappa_{c}=4 \times 10^{-4} \mathrm{ps}^{-1}$, and a vacancyrelated component $\tau_{v}=245 \mathrm{ps}$ with a trapping rate $\kappa_{v}=\mu_{v} x_{v}$, with $\mu_{v}=430 \mathrm{ps}^{-1}$ as given by Ref. [56]. The average positron lifetime $\bar{\tau}$ is in general reflected by the measured $\tau_{1 C}$ rather well (see Supplemental Material [18], Fig. S2). For very high $x_{v}$, however, $\tau_{1 C}$ might overestimate $\bar{\tau}$, which is just $230 \mathrm{ps}$ (open triangle) and not 243 ps (crossed triangle; for further discussion, see Supplemental Material [18], end of Sec. S3). The broken lines represent calculated positron lifetimes in the presence of just vacancies, the solid ones for the additional constant cluster component that was estimated to ensure that $\tau_{2+3} \sim 216 \mathrm{ps}$. Triangles mark special points discussed in the text.

measured with the high-resolution spectrometer $\mathrm{P}$ and shows that most positrons are not trapped in vacancies but in clusters. As experiments at $\mathrm{B}$ and $\mathrm{P}$ were carried out at different temperatures this points to the predominance of clusters that are deep, i.e., trap at room temperature, unlike the clusters created during short NA in another study that were partially shallow positron traps [9]. In Fig. 8, we now add a constant cluster contribution just big enough to bring down $\tau_{2+3}$ while keeping $\tau_{1 C}$ near the measured 163 ps and apply the three-state trapping model (full lines). As the lifetime $\tau_{2+3}=216 \mathrm{ps}$ is the result of a mixed contribution of $\tau_{2}=210 \mathrm{ps}$ and $\tau_{3}=$ $245 \mathrm{ps}$, trapping in vacancies is even lower than assumed above and the corresponding $x_{v}=2.5 \times 10^{-7}$ in the example given in Fig. 8 (split triangle). This is just about three times higher than the equilibrium vacancy fraction at $180^{\circ} \mathrm{C}, x_{v}=$ $8 \times 10^{-8}$ (see Fig. 10). Thus, short AA in LM can eliminate most vacancies while producing just few clusters.

After slower heating in oil, MS, or on the heating plate, the positron traps are much more densely distributed and fewer positrons annihilate in the bulk as reflected by the trap contribution $I_{2+3}$ that is now $\sim 80 \%$ instead of just $\sim 50 \%$ for fast heating; see Fig. 2(c). $\tau_{2+3}$ is similar to that in LM; see Fig. 2(b). Therefore, more clusters have formed during slower heating than during fast heating.

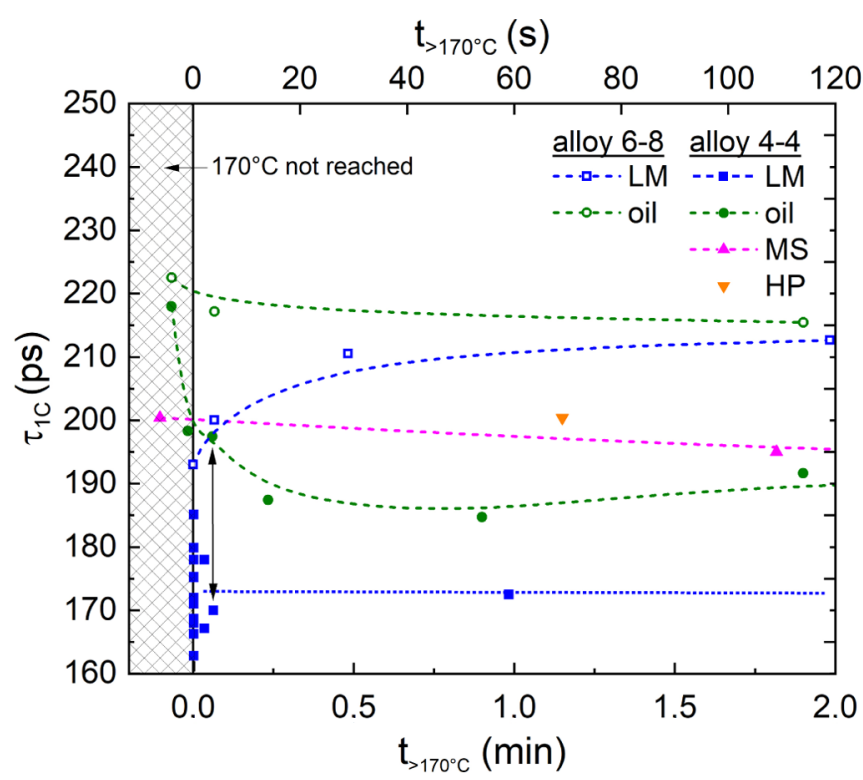

FIG. 9. Positron lifetimes $\tau_{1 C}$ measured in alloys 4-4 and 6-8 after AA in various media for up to $2 \mathrm{~min}$. Data are from Figs. 2(a) and 3 , but time axis is linear and corrected for the time the alloy has spent at temperatures below $170^{\circ} \mathrm{C}$, i.e., $0.9,6,11$, or $63 \mathrm{~s}$ were subtracted from the times in Figs. 2(a) and 3 for heating in LM, oil, MS, and on the heating plate, respectively. Negative values of $t$ (hatched area) indicate that a sample did not reach $170^{\circ} \mathrm{C}$ but will still need time $|t|$ to reach $170^{\circ} \mathrm{C}$. The vertical arrow compares two experiments in $\mathrm{LM}$ where $4 \mathrm{~s}$ were spent above $170^{\circ} \mathrm{C}$. The choice of $170^{\circ} \mathrm{C}$ is pracically motivated and does not have a physical background.

A problem encountered when comparing short AA at different heating rates is that of an ambiguous definition of ageing time. Figure 9 helps to compare the four different heating media by displaying the effective time spent above $170{ }^{\circ} \mathrm{C}$ for each measurement. In Fig. 2(a), for example, the two-sided arrow compares AA in LM for $5 \mathrm{~s}$ and that in oil for $10 \mathrm{~s}$. For heating in LM or oil, about 0.9 or $6 \mathrm{~s}$, respectively, are needed to reach $170{ }^{\circ} \mathrm{C}$ and therefore both samples spent about $4 \mathrm{~s}$ above $170^{\circ} \mathrm{C}$ as marked by the corresponding arrow in Fig. 9. This demonstrates that the magnitude of $\tau_{1 C}$ reduction during $\mathrm{AA}$ really depends on the heating rate up to $180^{\circ} \mathrm{C}$ and is not just an artefact of different holding times at the final temperature.

The scatter of experimental values of $\tau_{1 C}$ (and therefore also $\bar{\tau}$ ) in Fig. 2(a) and especially values much higher than $163 \mathrm{ps}$ are thought to be the consequence of slightly varying conditions inflicted by the manually conducted transfer from the ice water after quenching to the LM.

\section{Simulation of vacancy dynamics}

The thermokinetic software MatCalc allows us to simulate the loss of vacancies during complex heat treatment sequences [28]. The underlying physics is the FSAK model for vacancy loss [7]. In our case, vacancies are predominantly lost at dislocation jogs. Grain boundaries do not contribute notably to vacancy annihilation as the grains have grown very large (500 $\mu \mathrm{m}$ or more [8]) during solutionizing due to the absence of 


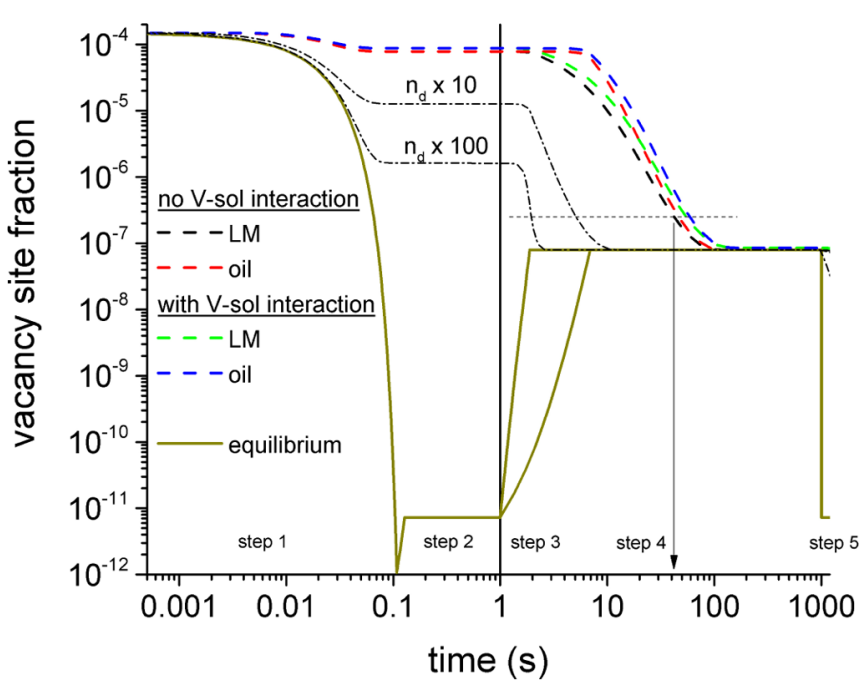

FIG. 10. MatCalc simulation of nonequilibrium vacancy site fraction in alloy 4-4 exposed to a temperature profile comprising five steps, namely (1) quenching from $540{ }^{\circ} \mathrm{C}$ to $0{ }^{\circ} \mathrm{C}$ at $-5000 \mathrm{~K} \mathrm{~s}^{-1}$; (2) brief holding at $20^{\circ} \mathrm{C}$ (time irrelevant) up to $t=1 \mathrm{~s}$; (3) heating to $180^{\circ} \mathrm{C}$ at two different rates $\left(170\right.$ and $25.5 \mathrm{~K} \mathrm{~s}^{-1}$ approximating $\mathrm{LM}$ and oil); (4) holding at $180^{\circ} \mathrm{C}$; and (5) quenching to $20^{\circ} \mathrm{C}$, after which positron lifetime is measured. The olive line is the equilibrium vacancy site fraction. The parameters chosen are dislocation density of $n_{d}=3 \times 10^{11} \mathrm{~m}^{-2}$ and jog fraction 0.02 (i.e., one jog every 50 atoms), leading to a jog site fraction of $2.5 \times 10^{-10}$. The grain size was $0.5 \mathrm{~mm}$ [8]. Vacancy-solute interaction energies were the same as used in Ref. [57]. The dash-dotted curves are variants of the broken black curve with 10 or 100 times higher dislocation jog densities. The short horizontal dashed line indicates $x_{v}=2.5 \times 10^{-7}$. All values have been multiplied by the entropy factor $e^{-S / k}=2$ not included in MatCalc, the value of which is from Ref. [47].

growth-retarding impurities. We model vacancy losses using the parameters suggested by Ref. [29], apply a temperature profile close to our experiment and obtain Fig. 10. A very high quenching rate $\left(5000 \mathrm{~K} \mathrm{~s}^{-1}\right)$ is required to obtain the postquenching (after steps 1 and 2) vacancy fraction $x_{v}=$ $7.5 \times 10^{-5}$ required to explain the observed positron lifetime of $230 \mathrm{ps}$ (Fig. 8). A quench rate of $900 \mathrm{~K} \mathrm{~s}^{-1}$ in water at $20{ }^{\circ} \mathrm{C}$ has been reported for 2.5-mm-thick samples [30] so that quenching of our just 1-mm-thick samples in ice water could be that fast. Subsequent heating to $180^{\circ} \mathrm{C}$ (step 3 ) leads to a decrease of vacancy fraction. Accepting the estimate of Fig. 8 that the vacancy fraction is $2.5 \times 10^{-7}$ after AA in LM (dotted horizontal line), we obtain a time of $\sim 40 \mathrm{~s}$ for this reduction by MatCalc calculation without vacancy-solute interactions, $\sim 55 \mathrm{~s}$ with them included. Additional vacancycluster interactions would further slow down vacancy losses, but we are presently not able to simulate them (read below). Increasing the dislocation density (or the jog fraction) by a factor of 10 or even 100 speeds up vacancy loss and the latter value would explain the experimentally found fast vacancy loss in just $\sim 1 \mathrm{~s}$. Such high dislocation densities have been reported for quenched Al-10Mg alloys $\left(5 \times 10^{13} \mathrm{~m}^{-2}\right)$ [31], $\mathrm{Al}-1.2 \mathrm{Si}$ alloys, and in pure $\mathrm{Al}$ following quenching $(2.2 \times$ $10^{13}-10^{14} \mathrm{~m}^{-2}$, derived from [32-34]). However, the vacancy fraction after quenching would also be lowered by such an increase of vacancy sink fraction and would go down to values incompatible with the high measured positron lifetimes after quenching. To solve this dilemma, dislocations could be thought to be created during quenching due to stresses caused by thermal gradients. If dislocations were progressively created predominantly towards the end of quenching at low temperatures a high vacancy fraction would be preserved.

Alternatively or in addition, vacancies could quickly form vacancy clusters during AA. They would have an only a small effect on positron lifetime due to their low number but significantly lower the fraction of free vacancies and therefore contribute to the fast decrease of $\tau_{1 C}$.

\section{Explanation of heating rate effect}

In Fig. 10, the heating rate to $180^{\circ} \mathrm{C}$ hardly influences the vacancy loss dynamics. This is because cluster formation is not taken into account. Solutes are transported to emerging clusters mediated by vacancies, but the emerging clusters then interfere strongly with vacancies [35]. This feedback situation is difficult to model without knowing the relevant interactions, which is why we can discuss this in a qualitative way only.

After solutionizing at $T_{\mathrm{SHT}}=540{ }^{\circ} \mathrm{C}$ and subsequent fast quenching, excess vacancies partition very quickly into free vacancies, $x_{v}^{\text {free }}$, and vacancies bound to solute atoms, $x_{v}^{\text {bound }}$. The fraction $\eta$ of free vacancies (of all vacancies, $x_{v}^{\text {tot }}$ ) can be calculated by a thermodynamic model [36] that has been successfully applied to Sn solute atoms in Ref. [37]:

$$
\begin{gathered}
\eta(T)=\frac{x_{v}^{\text {free }}}{x_{v}^{\text {tot }}}(T)=\frac{1+12 x_{s} \exp \left(E / R T_{\mathrm{SHT}}\right)}{1+12 x_{s} \exp (E / R T)}, \\
\text { with } x_{v}^{\text {free }}+x_{v}^{\text {bound }}=x_{v}^{\text {tot }},
\end{gathered}
$$

which has been evaluated in Fig. 11 for our case. Without any vacancy losses one could reversibly move up and down temperature and the vacancies would repartition accordingly into free vacancies and bound vacancy-solute complexes. Only bound vacancies (i.e., attached to solute atoms), fraction $(1-\eta)$, contribute to solute diffusion because they allow solute atoms to chance lattice sites. Whenever a bound solutevacancy pair meets other solutes or clusters, it might stick to those, after which the vacancy moves away again after a residence time $[38,39]$. The sticking probability $p_{\text {stick }}(T)$ will be higher for lower temperatures as it is governed by the (poorly known) binding energy between a solute and a cluster. We write for the rate of cluster volume growth $\dot{V}_{c}$

$$
\dot{V}_{c}=\Gamma_{v}(T) \underbrace{[1-\eta(T)] x_{v}^{\text {tot }}}_{x_{v}^{\text {bound }}} p_{\text {stick }}(T),
$$

where $\Gamma_{v}(T)$ is the jump frequency of a vacancy or solutevacancy complex, which markedly increases with temperature. In the presence of vacancy sinks, the free vacancy site fraction will decrease as shown in Fig. 10. During early ageing the rate of vacancy loss can be simplified to

$$
\dot{x}_{v}=-\Gamma_{v}(T) \underbrace{\eta(T) x_{v}^{\text {tot }}}_{x_{v}^{\text {free }}} x_{\text {sink }},
$$

where $x_{\text {sink }}$ is the temperature-independent vacancy sink (essentially dislocation jog) fraction. Combining Eqs. (2) and (3) 


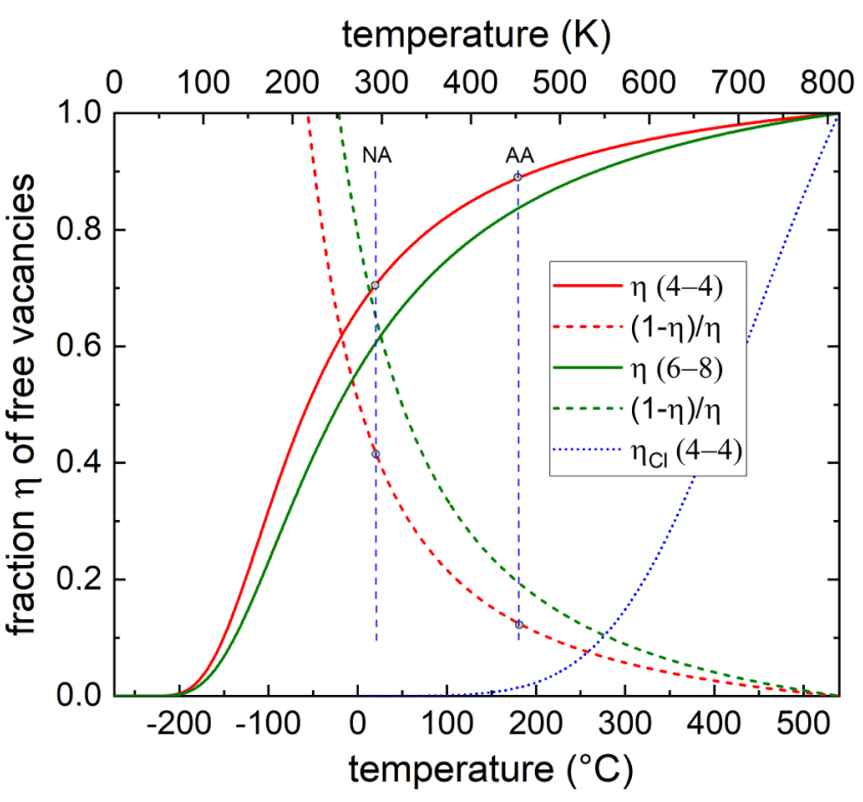

FIG. 11. Fraction $\eta(T)$ of the vacancies quenched-in from $T_{\mathrm{SHT}}=540^{\circ} \mathrm{C}$ that are free (as opposed to attached to solute atoms) as calculated from the thermodynamic model of $[36,37]$ expressed by Eq. (1), solid lines. A binding energy $E=50 \mathrm{meV}$ between a solute atom and a vacancy is assumed and $x_{s}=8 \times 10^{-3}$ or $1.4 \times 10^{-2}$ for alloys $4-4$ or $6-8$, respectively. The dashed lines represent the factor $(1-\eta) / \eta$ occuring in Eq. (4). The exemplary curve for a cluster containing nine atoms is based on $E=450 \mathrm{meV}, x_{s}=3 \times 10^{-5}$ and obtained by replacing 12 by 37 neigbors in Eq. (1).

we obtain the ratio of clustering vs vacancy loss:

$$
\frac{\dot{V}_{c}}{\left|\dot{x}_{v}\right|}=\frac{1-\eta(T)}{\eta(T)} \frac{p_{\text {stick }}(T)}{x_{\text {sink }}} .
$$

This quantity is higher for $20^{\circ} \mathrm{C}$ than for $180{ }^{\circ} \mathrm{C}$ as both factors decrease with $T$ (dashed line in Fig. 11 and the above mentioned behavior of $p_{\text {stick }}$ ). Thus, during NA many clusters are formed while vacancies are lost slowly and the positron lifetime drops from an initially high value to a typical cluster value, i.e., 215 ps; see the Supplemental Material [18], Fig. $\mathrm{S} 1$ (a). During instant AA (fictitious infinitely high heating rate to $180{ }^{\circ} \mathrm{C}$ ), best represented by AA in LM, fewer clusters are formed and more vacancies are lost, Eq. (4), and therefore the positron lifetime decreases to values much below 215 ps; see Figs. 2(a) and 3. Of course this happens many orders of magnitude faster during AA than during NA.

Equation (4) is valid for the initial ageing stage. Once clusters have been formed the picture changes. Clusters trap vacancies much more efficiently than solute atoms. According to Ref. [38], the binding energy in Eq. (1) should be replaced by $N \times E$ for $N$ equal atoms in a cluster. Figure 11 shows how low the fraction of free vacancies for $N=9$ gets. Moreover, vacancies are trapped in clusters for a longer time [38]. Vacancies in clusters can induce internal ordering processes and displace clusters. Thus, they contribute to further clustering while reducing vacancy losses, i.e., the ratio in Eq. (4) is further increased. There is a positive feedback: clustering retains vacancies and vacancies enable further clustering.
This explains qualitatively the observations during slow heating to $180^{\circ} \mathrm{C}$ : During the few seconds at lower temperatures, $20^{\circ} \mathrm{C}$ and above, clustering sets in and relatively few vacancies are lost. At higher temperatures and finally at $180^{\circ} \mathrm{C}$, this trend continues and the ratio in Eq. (4) remains high. In contrast, after instant heating to $180{ }^{\circ} \mathrm{C}$ the ratio in Eq. (4) is initially smaller and remains small as clustering activity is low due to the fewer vacancies remaining in the system.

In the above considerations attractive solute-vacancy and cluster-vacancy interactions have been assumed although claims of repulsive interactions, e.g., between $\mathrm{Mg}$ and vacancies exist [40] and much of the literature dataespecially older literature-are not consistent (see overview in Ref. [41]). In the light of the latest literature, most nextneighbor-interactions are indeed attractive, while on some more distant shell interactions can turn to repulsive [42-44].

Another point to consider is the role of impurities. Especially for atoms like $\mathrm{Sn}, \mathrm{In}, \mathrm{Cd}$, vacancy-impurity interactions are much stronger than interactions of vacancies with the main elements $\mathrm{Mg}$ and $\mathrm{Si}$ (e.g., $0.24-0.3 \mathrm{eV}$ for $\mathrm{Sn}$ [37] vs $\sim 0.05$ for $\mathrm{Si}$ ). However, the alloys used in this study are very pure and there is no impurity with a level above 10 ppm. Sn has the highest interaction energy of all and has been shown to retard natural ageing at levels of $40 \mathrm{ppm}$ and higher. However, the influence on artificial ageing is low [37], which is why impurities should have a negligible influence in our case.

\section{Further experiments related to short AA times}

Comparing different alloys provides more insight into the phenomena during short AA. Figure 4 compares values for $\tau_{1 C}$ after $1 \mathrm{~s}$ of AA in LM for six alloys as a function of solute content (solid symbols). Higher solute content clearly causes a higher $\tau_{1 C}$, implying that fewer vacancies are lost and/or more clusters are formed under the same conditions. This finding is also reflected by a two-component decomposition of positron lifetime that was possible in one case for alloy 6-8 (first red point in Fig. 3). Here, $84 \%$ of all positrons are trapped by clusters or vacancies compared to less than 50\% in alloy 4-4. In the literature, a similar value of $\sim 90 \%$ is given, however after slower heating [45]. Therefore, alloy 6-8 contains more vacancies and clusters than alloy 4-4 after a similar short ( $1 \mathrm{~s}$ in LM) AA treatment. There are two reasons for this: first, vacancies are more likely to interact with solute atoms and to form clusters when the solute content is high, which helps to retard vacancy annihilation. The first term in Eq. (4) is higher in alloy 6-8; see Fig. 11. Second, as discussed above, some clusters might have formed already during quenching and such formation is expected to be more pronounced for higher solute contents $[9,46]$. Consequently, even after heating up alloy 6-8 at the fastest rate $\left(0.3 \mathrm{~s}\right.$ at $300{ }^{\circ} \mathrm{C}$ in $\left.\mathrm{LM}\right) \tau_{1 C}$ is still $190 \mathrm{ps}$, much higher than the 163 ps measured in alloy 4-4 after $1 \mathrm{~s}$ in $\mathrm{LM}$ at $180^{\circ} \mathrm{C}$.

If such pre-existing clusters in alloy 6-8 have this effect, clusters formed in alloy 4-4 after some natural ageing before AA has been carried out should have the same effect. This is actually true as shown in Fig. 4 (red symbols) where up to 80 min of natural preageing (NPA) in alloy 4-4 lead to a similar 
effect as increasing the total solute content to $1.4 \mathrm{wt} \%$ as in alloys 4-10, 6-8, 8-6, and 10-4.

Finally, we look at changes of electrical resistivity caused by $10 \mathrm{~s}$ of AA, Fig. 6. AA is expected to change resistivity in 3 ways: (i) any loss of vacancies reduces resistivity with an estimated rate of $1.9 \mu \Omega \mathrm{cm} / \mathrm{at} \%$ [47] (not known with great precision $[48,49]$ ). Taking the vacancy fraction of $7.5 \times 10^{-5}$ used above for the quenched state, the reduction would be $0.014 \mu \Omega \mathrm{cm}$ for a loss of all vacancies, which is $2.1 \%$ or $1.4 \%$ of the absolute resistivity given in Fig. 6 for our alloys 4-4 or 6-8, respectively. (ii) Clustering is known to increase resistivity [50]. The maximum increase during very long NA is $\sim 6 \%$ for alloy $6-8[13,16]$. (iii) Solute depletion from the matrix eventually decreases resistivity, but this contribution should be small after $10 \mathrm{~s}$ of AA. The wires exhibit large equiaxed grains $(\sim 150 \mu \mathrm{m})$ due to full recrystalization during solutionizing and an effect of wire drawing on resistivity can be excluded.

In alloy $4-4$ aged in LM, the resistivity reduction by $1 \%$ is therefore compatible with the loss of most vacancies and some cluster formation that does only partially compensate the effect of vacancy loss. In alloy 6-8 heated in oil, in contrast, the increase by clustering is stronger than the reduction by vacancy loss, hence a net increase. As electrical resistivity and positron lifetime are influenced by vacancy loss (reducing both) and clustering (increasing both) in the same way, the two observables are correlated; see Fig. 6.

\section{B. Intermediate AA times}

After short ageing has reduced $\tau_{1 C}$ in alloy $4-4, \tau_{1 C}$ increases again in intermediate ageing stages; see Fig. 2(a). In alloy 6-8, the minimum is very shallow and $\tau_{1 C}$ is almost constant (Fig. 3). For all the alloys and heating conditions, 100-200 min of AA leads to $\tau_{1 C}$ values between 208 and 219 ps, pointing at largely saturated positron trapping into the precipitates typically formed during AA.

The stage of constant $\tau_{1 C}$ for alloy 6-8 corresponds to the highest increase of hardness; see Fig. 5. Precipitates grow from GP zones to $\beta$ " phase here but $\tau_{1 C}$ changes little because positron trapping is already saturated. In alloy 4-4, however, $\tau_{1 C}$ increases a lot, up to $200 \mathrm{~min} \mathrm{AA}$, but hardness changes only marginally. Here, $\tau_{1 C}$ increases so much because at the positron lifetime minimum, trapping into clusters is not saturated and forming small but easily shearable precipitates with a positron lifetime of $\tau_{2+3} \sim 216 \mathrm{ps}$-Fig. 2(b) - has an immediate effect on $\tau_{1 C}$ but not on hardness.

Studies in the literature on similar alloys show a comparable behavior [24,45]. Altogether, these ageing stages are not very interesting from the viewpoint of positron annihilation since the lifetime values obtained are rather insensitive to the microscopic configuration. The slight ups and downs observed in the $\tau_{1 C}$ curves are hard to interpret without excessive speculation.

\section{Long AA times}

AA for $\geqslant 200 \mathrm{~min}$ leads to an increase of $\tau_{1 C}$ to values above 220 ps and eventually to 235 ps for both alloys and irrespective of heating conditions. Figure 2(b) shows that $\tau_{2+3}$ for alloy 4-4 increases to $230-240$ ps for long AA times. Obviously, the character of the positron traps changes upon AA. A vacancy-related trap cannot be the reason as all vacancies are in thermal equilibrium after long AA (Fig. 10). In accordance with Refs. [25,45], we assume that additional open volume associated with the partial incoherency of the precipitates formed at this stage causes the increase of $\tau_{2+3}$. As the precipitation sequence involves a transition from early GP zones to $\beta$ " and/or $\beta$, the degree of lattice mismatch and lack of coherency increases in this order. $\beta$, formation is associated with a global shrinkage of a sample due to the removal of $\mathrm{Mg}$ from the matrix that overcompensates the expansion of $\beta$, [51,52] and tensile stresses around individual $\beta$ ' precipitates build up (other than for $\beta$ " where the stresses are compressive). This facilitates the formation of open volume. As $I_{2+3}$ remains at $\sim 80 \%$ but $\tau_{2+3}$ increases, $\tau_{1 C}$ is notably increased to almost 235 ps; see Fig. 2(b). The increase observed is much more pronounced in this study than in other works [24,25]. Only Resch et al. [45] find a comparable increase to 231 ps after 2 weeks of AA at $180^{\circ} \mathrm{C}$. Overageing for 1 week at $180^{\circ} \mathrm{C}$ lets precipitates coarsen and hardness correspondingly decreases as dislocations are increasingly able to bypass them via the Orowan mechanism. In contrast, the value for $\tau_{1 C}$ remains high. This shows that even the coarsened precipitates trap all positrons efficiently and prevent the appearance of a bulk component that would reduce $\tau_{1 C}$ again. The reason for this lies in the extended nature of the precipitates and the large value for the specific trapping rate of their interfaces [53] as has been shown by using the model and formalism given in Ref. [54].

The increase of $\tau_{1 C}$ actually takes place at a later time in alloy 6-8 than in alloy 4-4 (blue arrow in Fig. 5). As ageing proceeds faster in alloy 6-8 than in 4-4 (expressed by faster hardening, green arrow) this requires attention. The fast $\tau_{1 C}$ increase coincides with fast hardening in alloy 4-4 as the black dash-dotted line shows but not in alloy 6-8. One possibility is that in alloy 4-4 hardening is mainly driven by formation of the $\beta$ ' phase and not of $\beta$ ". The already mentioned long positron lifetime in $\beta$, would then cause the rapid increase. In fact, a recent transmission electron microscopic study has shown for an alloy similar to our alloy 4-4 that $\beta$ ' forms directly during AA without the need to first form $\beta$ " [55].

\section{CONCLUSIONS}

Artificial ageing (AA) of solutionized and quenched Al$\mathrm{Mg}-\mathrm{Si}$ alloys of different compositions can decrease the onecomponent positron lifetime $\tau_{1 C}$ by up to 80 ps in just a few seconds.

In the lean alloy $4-4$ heated to $180^{\circ} \mathrm{C}$ within $1 \mathrm{~s}$, vacancies diffuse to sinks quickly and hardly assist clustering. The state produced is that of a sparse population of clusters and some residual excess vacancies. Therefore, positrons annihilate with a low lifetime in the bulk lattice since many of them are not trapped. The fast vacancy loss observed points at a large site fraction of vacancy sinks that might be formed during quenching. Vacancy clustering could also contribute to the decrease of positron lifetime.

The positron lifetime after AA is always longer and hence the trap density higher when clusters or precipitates 
are formed before or during AA, thereby limit further vacancy losses, which in turn enables further clustering-a self-amplifying effect. This happens whenever the following occur:

(i) The alloy contains more solute: in this case, more clusters are formed already during quenching after solutionizing.

(ii) The alloy is heated slowly to $180^{\circ} \mathrm{C}$ : in this case, clustering sets in at lower temperatures, which then delays losses of vacancies at increasing temperature.

(iii) The alloy is naturally preaged before AA: the clusters formed help to retain vacancies.

Only because positron lifetime is so sensitive to minimal changes of open volume in crystalline systems do these phenomena give rise to such pronounced positron lifetime changes. Electrical resistivity as the second most sensitive method yields only weak signals, hardness and DSC measurements none.
Knowing heating rate effects in more detail could help us to understand hitherto unexplained property variations found in industrial alloy processing where this quantity is usually not controlled very well. Such effects could also be harnessed to improve industrial preageing and artificial ageing practices.

\section{ACKNOWLEDGMENTS}

We would like to thank J. Hirsch from Hydro Aluminium Bonn for providing the alloys and the Deutsche Forschungsgemeinschaft for funding (Grant No. Ba 1170/22). Q.G. and X.Z. thank the China Scholarship Council (CSC) for research fellowships (Grants No. 201506170013 and No. 201706050074). We are grateful to R. Würschum for pointing out that the formalism given Ref. [54] can be used to show that saturated positron trapping can take place even in overaged alloys.
[1] J. Banhart, in ASM Handbook, Heat Treating of Nonferrous Alloys, edited by G. E. Totten and D. S. Mackenzie (ASM International, Materials Park, OH, USA, 2016), p. 214.

[2] V. Fallah, A. Korinek, N. Ofori-Opoku, B. Raeisinia, M. Gallerneault, N. Provotas, and S. Esmaeili, Acta Mater. 82, 457 (2015).

[3] S. J. Andersen, H. W. Zandbergen, J. Jansen, C. Traeholt, U. Tundal, and O. Reiso, Acta Mater. 46, 3283 (1998).

[4] C. D. Marioara, S. J. Andersen, J. Jansen, and H. W. Zandbergen, Acta Mater. 49, 321 (2001).

[5] S. J. Andersen, C. D. Marioara, A. Froseth, R. Vissers, and H. W. Zandbergen, in Electron Microscopy and Analysis 2003, edited by S. McVitie and D. McComb, Institute of Physics Conference Series (IOP Publishing, Oxford, England, 2004).

[6] J. H. Chen, E. Costan, M. A. van Huis, Q. Xu, and H. W. Zandbergen, Science 312, 416 (2006).

[7] F. D. Fischer, J. Svoboda, F. Appel, and E. Kozeschnik, Acta Mater. 59, 3463 (2011).

[8] J. Banhart, M. D. H. Lay, C. S. T. Chang, and A. J. Hill, Phys. Rev. B 83, 014101 (2011).

[9] M. Liu, J. Čižek, C. S. T. Chang, and J. Banhart, Acta Mater. 91, 355 (2015).

[10] M. D. H. Lay, H. S. Zurob, C. R. Hutchinson, T. J. Bastow, and A. J. Hill, Metall. Mater. Trans. A 43, 4507 (2012).

[11] R. Krause-Rehberg and H. S. Leipner, Positron Annihilation in Semiconductors (Springer-Verlag, Heidelberg, 1999).

[12] F. de Geuser and B. Gault, Acta Mater. 188, 406 (2020).

[13] J. Banhart, C. S. T. Chang, Z. Q. Liang, N. Wanderka, M. D. H. Lay, and A. J. Hill, Adv. Eng. Mater. 12, 559 (2010).

[14] It was also attempted to show a difference in the DSC signal obtained on samples after 10-s AA in LM and oil following the standard protocol given in Ref. [15]. While as-quenched samples feature a pronounced clustering and dissolution signal as described before [16], 10-s AA removes this peak and the corresponding dissolution trough almost completely. AA in oil and LM give rise to a very similar signal. Hence, DSC is not sensitive enough to detect the differences seen by positron annihilation and resistivity measurement.
[15] Z. Yang, Z. L. Liang, D. Leyvraz, and J. Banhart, Materialia 7, 100413 (2019).

[16] M. Madanat, M. Liu, and J. Banhart, Acta Mater. 159, 163 (2018).

[17] Q. Peng, X. Wei, J. Ding, J. Yang, and X. Yang, Int. J. Energy Res. 32, 1164 (2008).

[18] See Supplemental Material at http://link.aps.org/supplemental/ 10.1103/PhysRevMaterials.4.063608 for additional information related to positron lifetime data acquisition, handling, and analysis.

[19] F. Bečvář, J. Čižek, I. Procházka, and J. Janotová, Nucl. Instrum. Methods Phys. Res. Sect. A 539, 372 (2005).

[20] H. E. Schaefer, R. Gugelmeier, M. Schmolz, and A. Seeger, Mater. Sci. Forum 15-18, 111 (1987).

[21] M. Puska and R. M. Nieminen, J. Phys. F: Metal Phys. 13, 333 (1983).

[22] C. Corbel and R. P. Gupta, J. Phys. Lett. 42, 547 (1981).

[23] O. Melikhova, J. Kuriplach, J. Čižek, and I. Prochazka, Appl. Surf. Sci. 252, 3285 (2006).

[24] J. Buha, P. R. Munroe, R. N. Lumley, A. G. Crosky, and A. J. Hill, in 9th International Conference on Aluminium Alloys, edited by J. F. Nie, A. J. Morton, and B. C. Muddle (Institute of Materials Engineering Australasia, North Melbourne, Victoria, Australia, 2004), p. 1028.

[25] T. E. M. Staab, R. Krause-Rehberg, U. Hornauer, and E. Zschech, J. Mater. Sci. 41, 1059 (2006).

[26] B. Klobes, K. Maier, and T. E. M. Staab, Philos. Mag. 95, 1414 (2015).

[27] R. K. W. Marceau, G. Sha, R. Ferragut, A. Dupasquier, and S. P. Ringer, Acta Mater. 58, 4923 (2010).

[28] MatCalc 6 - The Materials Calculator (Institut für Werkstoffwissenschaft und Werkstofftechnologie, TU Wien), www.matcalc.at, accessed 16.05.2020.

[29] A. Falahati, P. Lang, and E. Kozeschnik, Mater. Sci. Forum 706-709, 317 (2012).

[30] S. Pogatscher, H. Antrekowitsch, H. Leitner, T. Ebner, and P. J. Uggowitzer, Acta Mater. 59, 3352 (2011). 
[31] M. Kubota, J. F. Nie, and B. C. Muddle, Mater. Trans. 45, 3256 (2004).

[32] E. Ozawa and H. Kimura, Acta Metall. 18, 995 (1970).

[33] E. Ozawa and H. Kimura, Mater. Sci. Eng. 8, 327 (1971).

[34] P. B. Hirsch, J. Silcox, R. E. Smallman, and K. H. Westmacott, Philos. Mag. 3, 897 (1958).

[35] P. Lang, Y. V. Shan, and E. Kozeschnik, Mater. Sci. Forum 794796, 963 (2014).

[36] M. F. Francis and W. A. Curtin, Acta Mater. 106, 117 (2016).

[37] S. Pogatscher, H. Antrekowitsch, M. Werinos, F. Moszner, S. S. A. Gerstl, M. F. Francis, W. A. Curtin, J. F. Löffler, and P. G. Uggowitzer, Phys. Rev. Lett. 112, 225701 (2014).

[38] H. S. Zurob and H. Seyedrezai, Scr. Mater. 61, 141 (2009).

[39] I. A. Girifalco and H. Herman, Acta Metall. 13, 583 (1965).

[40] C. Wolverton, Acta Mater. 55, 5867 (2007).

[41] M. Liu and J. Banhart, Mater. Sci. Eng. A 658, 238 (2016).

[42] R. Kobayashi, D. Giofré, T. Junge, M. Ceriotti, and W. A. Curtin, Phys. Rev. Mater. 1, 053604 (2017).

[43] T. Saito, E. A. Mortsell, S. Wenner, C. D. Marioara, S. J. Andersen, J. Friis, K. Matsuda, and R. Holmestadt, Adv. Eng. Mater. 20, 1800125 (2018).

[44] O. I. Gorbatov, A. Y. Stroev, Y. N. Gornostyrev, and P. A. Korzhavyi, Acta Mater. 179, 70 (2019).
[45] L. Resch, G. Klinser, E. Hengge, R. Enzinger, M. Luckabauer, W. Sprengel, and R. Würschum, J. Mater. Sci. 53, 14657 (2018).

[46] M. Liu Ph.D. thesis, Technische Universität Berlin, 2014, doi.10.14279/depositonce-4207.

[47] A. Khellaf, A. Seeger, and R. M. Emrick, Mater. Trans. 43, 186 (2002).

[48] Y. Fukai, Philos. Mag. 20, 1277 (1969).

[49] F. R. Fickett, Cryogenics 11, 349 (1971).

[50] C. Panseri and T. Federighi, J. Inst. Met. 94, 99 (1966).

[51] E. Hengge, R. Enzinger, M. Luckabauer, W. Sprengel, and R. Würschum, Philos. Mag. Lett. 98, 301 (2018).

[52] R. Enzinger, E. Hengge, W. Sprengel, and R. Würschum, J. Mater. Sci. 54, 5083 (2019).

[53] R. Würschum (private communication).

[54] R. Würschum, L. Resch, and G. Klinser, Phys. Rev. B 97, 224108 (2018).

[55] Y. X. Lai, B. C. Jiang, C. H. Liu, Z. K. Chen, C. L. Wu, and J. H. Chen, J. Alloys Compd. 701, 94 (2017).

[56] G. M. Hood and B. T. A. McKee, J. Phys. F: Met. Phys. 8, 1457 (1978).

[57] Z. Q. Liang, C. S. T. Chang, C. Abromeit, J. Banhart, and J. Hirsch, Int. J. Mater. Res. 103, 980 (2012). 